\title{
Knowledge, Practices and Attitude of Adolescent Females towards External Genital Organs Infection
}

\author{
*Amel RagabTolba ** Nadia Mohamed Fahmy, ***Amel Ahmed Hassan Omran***Aziza \\ Ibrahim Mohamed \\ * Benha nursing School ** Maternity and newborn health nursing, Faculty of nursing. Ain shams University \\ *** Obstetrics and women health Nursing, Faculty of Nursing, Benha University
}

\section{Abstract}

The aim of this study was to assess knowledge, practices and attitude of adolescent females towards external genital organs infection. Design: Descriptive study design was used. Setting: three faculties (art, law and education) at Benha University. Sample: multistage systematic random sample of twenty five percent of all first year academic students. Tools of data collection: self-administrative questionnaire sheet, reported practices assessment sheet and modified likert scale to assess of adolescent female attitude. Results: The total score of knowledge, practices and attitude was poor, unsatisfactory and negative respectively..Conclusion: Majority of adolescent females had poor knowledge, unsatisfactory practices and negative attitude regarding external genital organs infection. Recommendation: Developing of reproductive health awareness programs to enhance adolescent female's knowledge, practices, and attitude regarding external genital organs infection (riskfactors, early detection, proper treatment and follow up).

Key words: Toxemia of pregnancy, Nurses, knowledge , practical skills, mortality rate.

Introduction

Adolescent is the young married woman and grandmother in the future so it is important to take into consideration their reproductive health needs and help in solving the problems of adolescent females (Child and adolescent health and development, WHO report, 2013).

Adolescent females meetcritical events of health risks that may affect on consequences on their future motherhood. (Alkoly et al, 2011).

Vulva is the area of the body which has a unique immunological response because the vulvo vaginal tract, include foreign proteins and antigens important for reproduction (Noller, 2004)

Although. Vulvar diseases may present in a variety of conditions ranging from asymptomatic to chronic disabling conditions. Symptoms such as itching, fissuring, The International Society for the Study of Vulvovaginal Diseases recently devised relevant methods of classifying vulvar diseases as either "vulvar dermatoses" in cases that cause visible skin differences or "vulvar dysesthesia" 
vulvodynia with vulval pain)(Ridley, 2002).

External genital inflammation companied by erythema (vulvitis) is most significant sign of irritants or allergens. Identifying the maincause or risk factors help to achieve good treatment and having a meticulous history. Once identified, the cause should be managed by plain water tub soaks (three times per day initially). Some advocate bath products such as oatmeal colloidal to soothe, but plain water is often all that is impotant. But effective ways should be maintained to avoid recurrence (Carpenter and Rock, 2005).

Furthermore, there are little organisms that cause vulvitis without vaginitis. Group A streptococcus would be one example. Often there is a history of coexisting or preceding strep throat or impetigo and a penicillin agent would be indicated. Finally, dermopathies like lichen sclerosis and eczema can exist on the vulva necessitating mild to moderate potency corticosteroid ointments used sparingly. Using effective ways as plain water soaks and prevention of irritants \& allergens. (Jamieson and Sanfilippo, 2007).

Nurse has good role in managing vulvitis through counseling and education. Nurses must give health teaching to adolescence to prevent having vulvitis such as wear loose clothing, Choose cotton underwear. Hygiene the vulua by soaking for five minutes in lukewarm water to avoid any residue of lotions or other products. Pat dry, and use any prescribed medication or a soothing and substance such as Vaseline or olive oil (Louise, 2015).

\section{Significance of the study}

Adolescent girls are especially susceptible to reproductive tract infection because the weakness of mucosal defense mechanism and the immature lining of the cervix give low barrier against infections. Also, the thin lining and relatively low level of vaginal acidity leading

to infection (Ahmed and Yesmin, 2010).

Moreover, Needs regarding reproductive health of adolescents as a group have been largely ignored by the existing reproductive health services. There is insufficient information about the reproductive health needs and problems of adolescent females.

According to the estimates of the World Health Organization (WHO), reproductive health problems represented about eighteen percentage of the total global burden of diseases in 2001. Accounting 32 percent of the health burden between women in the childbearing period group worldwide (IDSK, 2011). At a gynecological external clinic for children and adolescents $23 \%$ of the patients were seen because of local genital symptoms (Piippo et al., 2014).

vulvitis is the most common gynecological problem among adolescent girls as it was found to affect all preparatory, secondary school and faculties students (Cemek,2015). In 2013 external genital organsinfection rates among 15- to 19-yearold female were considerably higher, at 3043.3 cases per 100,000 (Centers for disease control and prevention,2013).

Egyptian society adolescent female represent abroad sector of population and the majority of them are attached to different educational levels (primary, preparatory, secondary school and university education, It makes them more susceptible to external genital organ infection (Vulvitis).As they use a public toilets in their learning setting,

As well as, Egyptian females' university students receive insufficient reproductive health education through the formal education in schools \& university system (Hanafy et al., 2012). 


\section{Aim of the study}

The aim of the present studywas to assess knowledge, practices and attitude of adolescent females towards external genital organs infection.

\section{Research question}

To what is the extent of the degree of knowledge, practices \&attitude of the adolescent females towards the external genital organs infection?

\section{Subjects \& Methods}

\section{Design:}

A descriptive design was utilized.

\section{Setting:}

The study was conducted at three faculties (Twenty five percent from the total twelve faculties) affiliated at Benha University. (Faculty of arts, Faculty of education, and Faculty of law)

\section{Sampling:}

Type: Multistage systematic random.

\section{Size and Technique}

- $\quad$ Sample number 440 female's students.

- Twenty five percent (about three faculties) from the total twelve faculties at Benha University were randomly selected (simple random sample).

- The researcher wrote the number of the faculties on bits of paper, put them in a box mix up thoroughly and pick up the specified number from this box by method of lottery through mixing of identical bits of paper would ensure equal chance of selection of any of them.

- Twenty five percent of first year female students of each faculty, are selected the adolescent females according to the student's lists every fourth one with the inclusion criteria. (System icrandom sample).

- The total number of students of selected faculties (art, education and law) were $(600,708$ and 452$)$ respectively.

- The total sample size were $(150,177$ and 113)respectively

- Finally equaled 440 females students

\section{Criteria:}

Inclusion: Free from medical problems as diabetes mellitus and hypertension.

Exclusion: Married adolescent girls

\section{Tools of data collection:}

\section{I- assessment sheet:}

Self-administered questionnaire sheets which consisted of two parts:

1) Socio- demographic data: This part intended to collect data related to sociodemographic characteristics such as (name, age, residence, medical history......etc.)

2)Knowledge assessment sheet: was used to assess adolescent females knowledge regarding external genital organs infection as (definition, symptoms, risk factor, causes, complication, preventive measures and treatment......etc.).It was composed of (6) questions.

\section{Scoring system}

(1)-------------------- (correct answer) 
(0)------------------(incorrect answer)

In adequate $(<60 \%$ of total knowledge score).

Adequate $(60 \%-75 \%$ of total knowledge score).

\section{П- (Reported practices sheet):}

It was developed by the researcher after reviewing related literature (adika, et al.,( 2013); Umar,et al.,(2010 )and hamed A.G.,(2015)., It was written in simple Arabic language in the form of close and open ended questions.\&was used to assess adolescent females reported practices, It included 22 items as(Personal hygiene provided for external genital infection)\& (hygienic care during menstruation...... etc.).

\section{Scoring system}

(1)

(0)

(done)

(not done)

Unsatisfactory $\ldots . \quad(<60 \%$ of total practice score)

Satisfactory $\ldots(60 \%-75 \%$ of total satisfactory score).

\section{III- 3 points (Modified likert scale) :}

Modified likert scale was used to assess attitude of the adolescent females regarding external genital infection and it was adopted from (fakhri, etal,2012).it was composed of (17) items.

\section{Scoring system}

Each question is scored as follow (agree)

(1) (Uncertain)
(0)-------------------------- (disagree)

Positive attitude: ------- (> 75\% of total attitude score).

Uncertain attitude:------(60 -75\% of total attitude score).

Negative attitude: -------- $(<60 \%$ of total attitude score).

\section{Tools validity and reliability}

Content validity was done by three panel expertise in the specialty of (obstetrics \& gynecology) and (maternal health nursing). The developed tool was reviewed for appropriateness of items.

Testing reliability of proposed tools was done by Cronbach alpha test. The internal consistency of modified likert scale has been tested using Cronbach's alpha coefficient. Cronbach's alpha were (0.869).

\section{Ethical considerations:}

The aim of the study was explained.

An oral consent was obtained from each student

Each student can withdraw at any time.

Data was collected and treated confidentially.

\section{Pilot study:}

The Pilot study was $10 \%$ of the total number (44 female's students). It is designated to determine the time consumed for filling in the questionnaire sheet, and to

Identify clarity of the tool. Data obtained from the pilot study were analyzed, and accordingly necessary modifications were done such as rephrasing of sentence. 
The pilot study of adolescent female was excluded from the total sample.

\section{Field work (procedure)}

- The process of data collection was carried out from the beginning of February 2016 to to the end of july 2016.( about 6 months )

- The researcher visited the faculties according to ordering visit.

- The study setting was visited as follows (Arts firstly, Education secondly\& Law thirdly).

- The researcher met the students 3 times per week according to the student schedule in the spare time.

- In each faculty the following steps were done:

- $\quad$ greeting the students.

- explaining the aim nature of the study and the method of filling the tool of the study.

- The researcher distributed questionnaire sheet to all students in each selected faculty then selected the student according to inclusion criteria and exclusion of married adolescent females

the selected students were given first tool (assessment sheet) which include sociodemographic data(age, residence------- -,etc.) to be fulfilled \& then (knowledge assessment sheet) which included (definition, symptoms and management, etc.), any needed clarification was done by the researcher. Also (reported practices) tool were given to assess hygienic care during menstruation as reported by student.
Finally (Modified likert scale) were used to assess attitude of adolescent females toward external genital organs infection and time consumed for each sheet about (10-15) minutes.

The researcher collected the sheets from student in the same day.

The second visit was paid to collect data from the absent students.

These steps were carried out with all three faculties.

The visit to faculty of arts consumed two month, but education two month and two weeks while Law one month and two weeks.

\section{Limitations:}

Some of adolescent females refused to share in filling the tool due to the shame and shyness of study topic.

More devoted time and effort was required to fill the tool.

\section{Results}

Table (1) shows that $75.7 \%$ of them were recruited at age group from 19-20 years old, with mean age of $19.97 \pm 3.45 .67 .3 \%$ of them were resident at rural settings. In addition $40.2 \%$ of them were from faculty of education, moreover $51.1 \%$ of them had no family medical history.

Table (2) reveals that $48.0 \%, 56.4 \%$ of them had a correct knowledge regarding meaning of infection and meaning of external genital infection respectively, $68.4 \%$ of them had incorrect knowledge regarding severe itching as symptoms of external genital infection. 


\section{Results:}

Table (1): Distribution of the studied sample regarding to personnel characteristics. $(n=440)$

\begin{tabular}{|l|c|c|}
\hline \multicolumn{1}{|c|}{ Variable } & Frequency & \% \\
\hline Age in years & & 73.7 \\
\hline $19-$ & 101 & 23.0 \\
\hline $20-$ & 6 & 1.3 \\
\hline$\geq 21$ & & $\mathbf{1 9 . 9 7 \pm 3 . 4 5}$ \\
\hline Mean \pm SD & 144 & 32.7 \\
\hline Residence & 296 & 67.3 \\
\hline Urban & & 34.1 \\
\hline Rural & 150 & 40.2 \\
\hline Faculty & 177 & 25.7 \\
\hline Faculty of arts & 113 & 23.2 \\
\hline Faculty of education & & 19.3 \\
\hline Faculty of law & 102 & 6.4 \\
\hline Family medical history & 85 & 51.1 \\
\hline diabetes mellitus diseases & 28 & \\
\hline hypertensive diseases & 225 & \\
\hline cardiac diseases & & \\
\hline No & & \\
\hline
\end{tabular}

Table (2): Distribution of the studied sample regarding their general knowledge about external genital infection. $(n=440)$

\begin{tabular}{|l|c|c|c|c|}
\hline \multirow{2}{*}{ Item } & \multicolumn{2}{|c|}{ Correct } & \multicolumn{2}{c|}{ Incorrect } \\
\cline { 2 - 5 } & No & $\%$ & No & \% \\
\hline Meaning of infection & 211 & 48.0 & 229 & 52.0 \\
\hline Meaning of external genital infection & 248 & 56.4 & 192 & 43.6 \\
\hline $\begin{array}{l}\text { Symptoms of external genital organ } \\
\text { infection }\end{array}$ & & & & \\
\hline Severe itching & 139 & 31.6 & 301 & 68.4 \\
\hline Redness and swelling in the vulva & 164 & 37.3 & 276 & 62.7 \\
\hline Whitish patches on the vulva & 197 & 44.8 & 243 & 55.2 \\
\hline Vaginal discharge & 172 & 39.1 & 268 & 60.9 \\
\hline Small skin crack & 178 & 40.5 & 262 & 59.5 \\
\hline $\begin{array}{l}\text { Causes of external genital organ } \\
\text { infection }\end{array}$ & & & & \\
\hline $\begin{array}{l}\text { Using of product increase sensitivity } \\
\text { such as perfumed soap and colored toilet } \\
\text { paper }\end{array}$ & 175 & 39.8 & 265 & 60.2 \\
\hline Using of public bathes & & & & \\
\hline Not change pad during menstruation & 203 & 46.1 & 237 & 53.9 \\
\hline Weakness of immunity & 176 & 40.0 & 264 & 53.4 \\
\hline Bacteria, parasites and fungi & 195 & 44.3 & 245 & 50.0 \\
\hline Dryness with used clothes & 178 & 40.5 & 262 & 55.7 \\
\hline
\end{tabular}




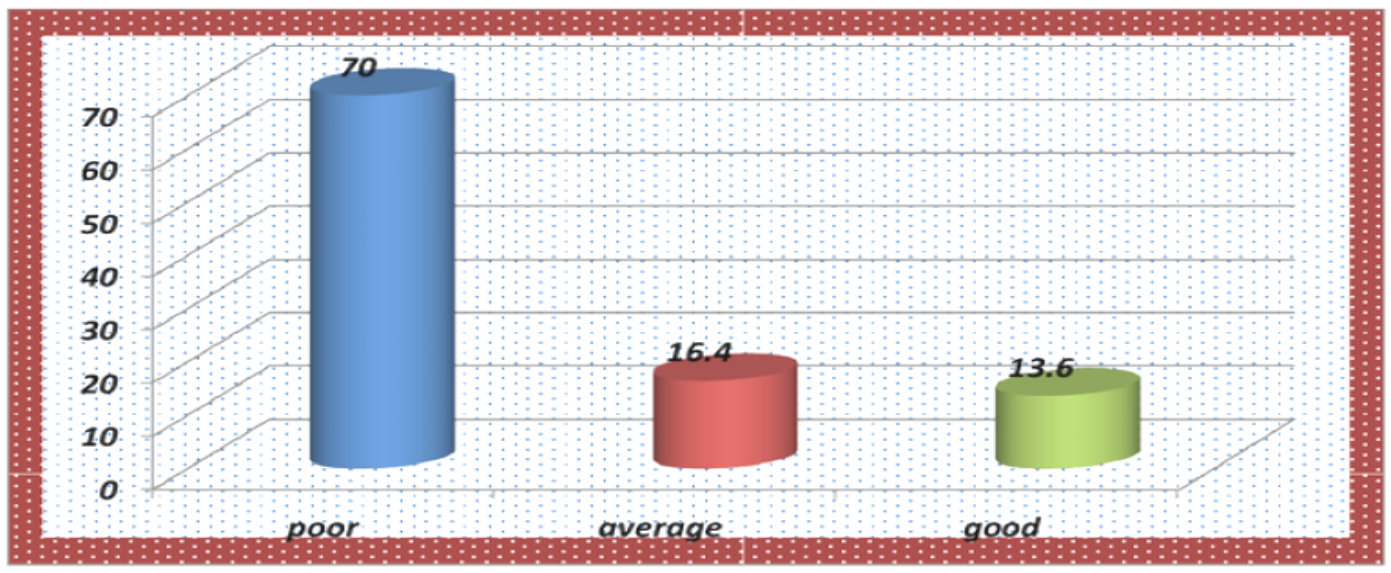

Figure (1): percentage distribution of total knowledge score of the studied sample regarding external female genital infection.

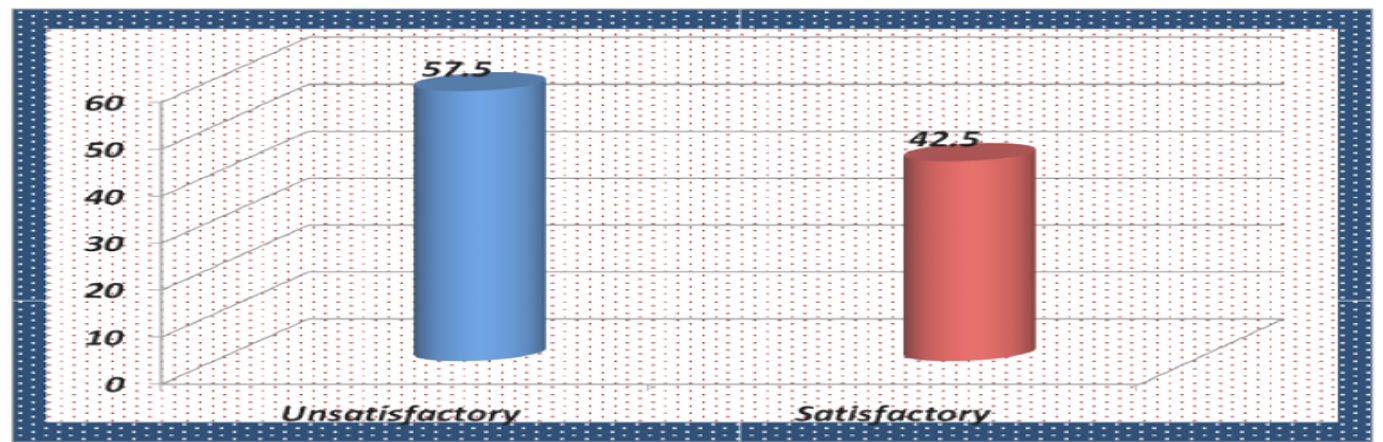

Figure (2): percentage distribution of total practice score of the studied sample regarding external female genital infect

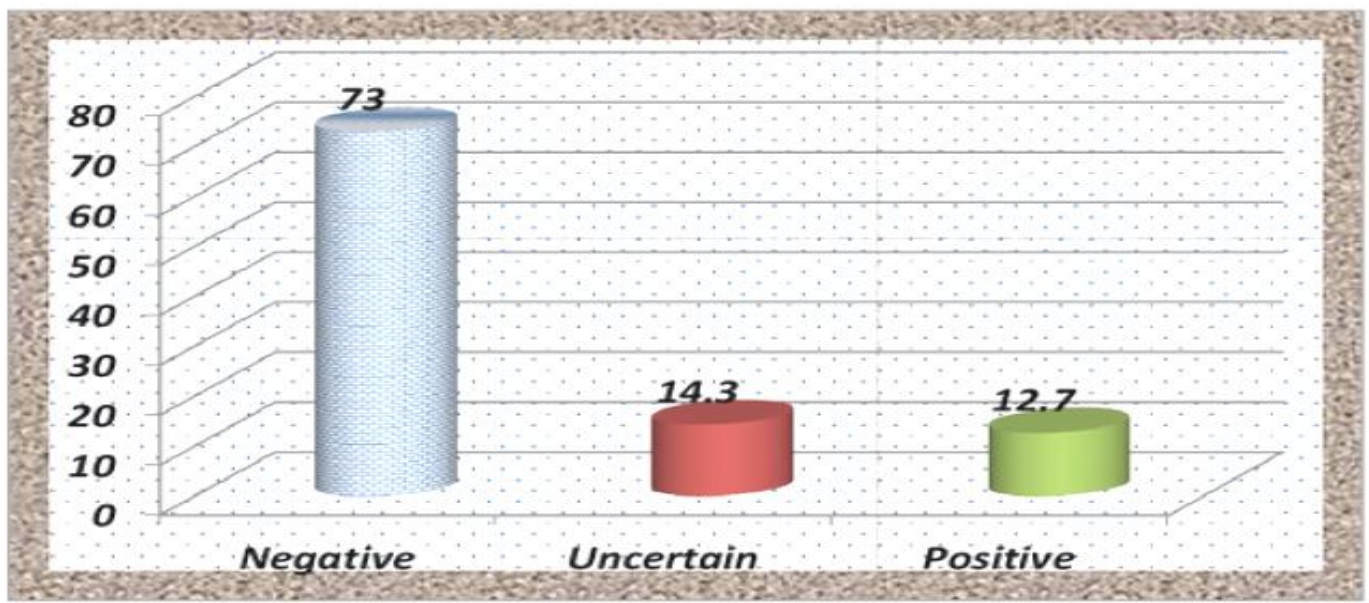


Discussion

The present study was carried out for the assessment of the knowledge, attitude and practice of adolescent females towards external genital organs infection. through: assessing the adolescent female's knowledge about external genital organs infection, assessing adolescent females reported practices regarding external genital organs infection, and assessing adolescent female's attitude toward external genital organs infection.

Regarding, the socio demographic characteristics of the study sample, the present study results showed that, the age of the study sample ranged from 19-20 years old. This finding is agreed with, by most of the previous studies Huebner. (2006) mentioned that, advanced female age compared with younger age, was associated with significantly high rates of infections, and infection complications

Concerning the residence, the present study results showed that, the majority of the study sample live at rural settings. Concerning the educational back-ground, the present study focused on university female. The different types of educations (faculties) have been considered. The study finding in agreement ElMinia study by Ibrahem et al,. (2007) who focus on university females.

Results of the present study indicated that, majority of students had had menarche at age of 14-16 years old. This study finding agrees with Dasgupta and Sarkar. (2008) who showed that, the age of menstruating girls ranged from 14 to 17 years. While, disagree with Thakre et al,. (2011) who found that, the age of the menstruating girls ranged from 12-17 years, with the maximum number of girls being between 13-14 years of age. The differences between study findings may be due to individuals' variations.

Regarding, the general knowledge about external genital infection among the studied female students, it was revealed that, vast majority of female students had incorrect knowledge regarding meaning of infection and meaning of external genital infection. These findings are in the same line with ElBeih et al,.( 2014) who reported that, most of the study sample had unsatisfactory knowledge regarding the definition of genital infection. This could be attributed to the insufficient basic information gained from their academic study.

The current study illustrated that the vast majority of the studied adolescent females had a poor knowledge regarding external genital infection( Figure 1). This may be attributed to insufficient education related to reproductive health related risks from their academic study. And the vast majority of them had mothers and friends as a source of knowledge; in addition the majority of the studied females did not go to the doctor when suffering from infectious problems and may not feel comfortable in discussing such issues with doctors. These findings came in the same line with El-Beih et al,. (2014) who pointed out that the majority of the studied students had unsatisfactory knowledge score level about reproductive tract infections.

Regarding studied adolescent female towards prevention of external genital organs, the present study revealed that the vast majority of them had unsatisfactory practice regarding menstrual and general hygiene practice (figure 2). This may be due to the insufficient knowledge and lack of awareness about hygienic practices that negatively affects their practice. This result agrees with Ahmed (2009), who reported that the majority of the adolescent girls had improper genital hygiene practice. These findings agree with Thakree et al.,( 2011), who revealed that practices of studied adolescents toward cleaning of the external genitalia was unsatisfactory. This may be attributed to insufficient education related to reproductive health related risks. 
Regarding practice of general care during menstruation nearly two thirds of the studied females don't take a shower during menstruation, This may be explained in view attributed that more than half of them disagreed that taking hot baths during menstruation decrease risk for infection. These findings are in agreement with Hassanen et al.,( 2004) who revealed that nearly two thirds of the girls had poor practice during menstruation. Also, Mubarak et al., (2004) in the study to assess experience of menarche among girls, it was reported that girls adopt some unhealthy practices during menstruation. These might be attributed to lack of proper health education programs regarding care during menstruation.

As regards studied female's attitude towards prevention of external female genital infection, the present study illustrated that the vast majority of them had negative attitude (figure 3). This may be due to the insufficient knowledge, unsatisfactory practice and lack of awareness regarding external female genital infection. The present study revealed that the vast majority of the studied female disagreement was the main pattern in relation to items related to attitude toward prevention of external genital infection.

\section{Conclusion}

There was vast majority of the studied adolescent females had a poor knowledge, unsatisfactory practices and a negative attitude regarding external genital organs infection.

Finally, the present study answered the research question and achieved the aim

\section{Recommendation:}

Develop reproductive health awareness programs targeted to adolescent females regarding vulvitis (risk factors, early detection, proper treatment and follow up) to improve their knowledge, practices, and attitude about external genital organs infection at their study setting.

Provide adolescent females with appropriate health care services, healthy habits booklets and pamphlet to meet their reproductive health needs,

Further researches are needed to investigate the effect of external genital organ infection on reproductive healthamong adolescentfemales.

\section{References}

Adika,V., Ayinde,M., and JackIde,I.,(2013):self care practices of menstrual hygiene among adolescents school going girls in amassoma community, International Journal of Nursing and midwifery Bayelsa State,5(5),99-105 August 2013 Available at http://www.academic journals. org/IJNM

Ahmed, R. \&Yesmin, K. (2010): Menstrual Hygiene: Breaking the Silence. [Online], Available:

http://www.wateraid.org/.../ch21_menstru al_hygiene_breaking_the_silence.

Ahmed, S. (2009):Urinary Tract Infections (UTI) among Adolescent Girls in Rural Karimangar District, Ap-K.A.P. Study, Indian J.Prev.Soc.Med; 40 (1):7.

Alkoly, T. Abd, Allah A. Alghamid, A. (2011): Nutritional Status and Eating Behaviors among Adolescents of Some Intermediate Schools in Jeddah. JKAU: Med. Sci. 2011; 18(2). DOI: 10.4197/Med. 18-2.X. Carpenter, SE.Rock, JA. (2005):Paediatric and Adolescent Gynecology, 3th. ed. Philadelphia: Lippincott Williams \& Wilkins. 
Carpenter, SE.Rock, JA. (2005):Paediatric and Adolescent Gynecology, 3th. ed. Philadelphia: Lippincott Williams \& Wilkins.

Cemek (2015): North American Society For Pediatric and adolescent gynecology, turkey, Elsevier inc

Centers for disease control and prevention,(2013); vaginal and vulvar cancers available at http://www. cdc.gov/cancer/vagvulv/index.htmupdate d 2012.accessed february19,2013

Child and adolescent health and development, WHO report, 18 July (2013):Available atwww.searo.who.int/entity/child adolescent/en

Dasgupta A. Sarkar M. (2008): Menstrual hygiene: How hygienic is the adolescent girl? Indian J Community Med Available at: http://www.ijcm.org.in/text.asp?2008/ $33 / 2 / 77 / 40872$

El-Beih, Amira.Dawah, Abd El- Moniem. Abd- El Aal, Ebtisam. Mohamed, Heba. (2014): Health Practices among Female University Students Regarding Prevention of Reproductive Tract Infections, International Journal infect, microbial.(1),29-33C 2012 Accepted 15september 2014

Hamed A.G.;(2015): The impact of genital hygiene practices on the occurrence of vaginal infection and the development of anursing fact sheet as prevention massage for vulnerable women, Journal of nursing and health science,4,(6)(nov.dec.2015),55-64 Available at http//www.iosr journals.org

Hanafy, S., ELsharkawy, O., Abdelbaqy, M., and Tewfik, M. (2012):Minding the Gap in Alexandria Talking to Girls in Schools about Reproductive Health,
Population Reference Bureau. Www. prb.org

Hassanen, R., Tosson, M., and AbdelKareem, H. (2004): Effect of Health Education on Training Program for Secondary School Students on Menstruation at Assuit Governorate. Bulletin of High Institute of Public Health; 34(3):575-94.

Huebner A. (2006): Adolescent growth and development. Available at: www.ext.vt.edu/pubs/family/350850/350-850.html.

Ibrahim, O., Morad, M., El Nashar, E., Mohamed, S., and Hafez, A. (2007): Prevalence of Symptoms and Complaints of Reproductive Tract infection among El Minia University Single Adolescent Female Educational Intervention. ELMinia Med., Bull., Vol .18,(2): 195-198.

Institute of Development Studies Kolkata (IDSK) (2011): Conference on Reproductive Morbidity \&Treatment Seeking Behavior in India. The Role of Demographic, Socio-economic \& Cultural Correlates.

Jamieson, Mary, Anne. Sanfilippo, Joseph S. (2007): Pediatric and Adolescent Patients. Available athttp://www.springer.com/978-0-38732327-5

Louise, Newson. (2015): Health and care information aboutVulvitismanagement in adolescent female. International Journal of nursing and midwifery, 98(2):218-223.

Mubarak, E., Mohey, A., and Kishk, N. (2004): Experience of Menarche among Girls in Alexandria: Community -Based Study, Alexandria 2003. Bulletin of High Institute of Public Health; 34(2): 335-56. 
Noller, KL. (2004): Vulva: the forgotten pelvic organ. Obstet Gynecol. 104: .913914.

Piippo, S., Lenko, H.,Vuento, R. (2004): Vulvar symptoms in paediatric and adolescent patients. ActaPædiatr; 89: 431-5. Stockholm. ISSN 0803-5253.

Ridley, CM. (2002): Classification of cutaneous vulvar disorder - ISSVD. In: Black MM, McKay M, Braude PR, et al., eds.Obstetric and Gynecologic Dermatology, 2nd edn. NewYork, NY: Mosby, 2002: 105-108.
ThakreSubhash B., Thakre, Sushama S. Reddy, Monica. Rathi, Nidhi. Pathak, Ketaki. Ughade\& Suresh. (2011): Menstrual Hygiene: Knowledge and Practice among Adolescent School Girls of Saoner, Nagpur District.Journal of Clinical and Diagnostic Research. 2011 October, (5): 1027-1033

Umar, M., Yusuf, N., and Musa, A., (2010): Menstruation and menstrual hygiene amongst adolescent school girls in kano,north western nigeria, African journal of reproductive health ,14(3)201208 ,sept

2010 